\title{
La Vengeance Fromondin, publiée par Jean-Charles Herbin
}

\section{Barbara Ferrari}

\section{(2) OpenEdition}

1 Journals

\section{Edizione digitale}

URL: http://journals.openedition.org/studifrancesi/9106

DOI: 10.4000/studifrancesi.9106

ISSN: 2421-5856

\section{Editore}

Rosenberg \& Sellier

\section{Edizione cartacea}

Data di pubblicazione: 1 juin 2008

Paginazione: 157

ISSN: 0039-2944

\section{Notizia bibliografica digitale}

Barbara Ferrari, «La Vengeance Fromondin, publiée par Jean-Charles Herbin», Studi Francesi [Online],

154 (LII | I) | 2008, online dal 30 novembre 2015, consultato il 09 janvier 2021. URL: http://

journals.openedition.org/studifrancesi/9106 ; DOI: https://doi.org/10.4000/studifrancesi.9106

Questo documento è stato generato automaticamente il 9 janvier 2021.

\section{(c) (i) (9)}

Studi Francesi è distribuita con Licenza Creative Commons Attribuzione - Non commerciale - Non opere derivate 4.0 Internazionale. 


\title{
La Vengeance Fromondin, publiée par Jean-Charles Herbin
}

\author{
Barbara Ferrari
}

\section{NOTIZIA}

La Vengeance Fromondin, publiée par Jean-Charles HERBIN, Abbeville, Paillart, 2005

(«Société des anciens textes français»), pp. 522.

1 La Vengeance Fromondin (VF) è trasmessa da un unico manoscritto (Paris, BnF, fr. 1622, $3^{\circ}$ quarto del XIII s.) di seguito alle canzoni di Garin le Loherain e Gerbert de Metz, di cui costituisce la continuazione. Il testo (246 lasse di decasillabi rimati, per un totale di 6672 versi) è stato oggetto di due edizioni parziali a fine Ottocento e di una integrale curata da S.R. Mitchneck nel 1935 (New-York, Inst. of French Studies Columbia University). L'edizione procurata da J.-Ch. Herbin costituisce senz'altro un progresso rispetto a quest'ultima, non solo perché vengono emendati numerosi errori di lettura, ma soprattutto per la ricchezza degli apparati complementari.

L'ampio studio introduttivo è organizzato in due sezioni principali: «Le manuscrit» (pp. 11-46) e «L'auteur» (pp. 47-101). Nella prima Herbin riesamina la posizione del ms. BnF, fr. 1622 (M) all'interno della tradizione della Geste des Loherains; tenendo conto dell'alternarsi di tre diverse mani nella confezione del manoscritto, e fondandosi sull'analisi puntuale della lingua dello scriba cui si deve la VF, lo studioso rimette in questione l'appartenenza del modello di questo testo alla famiglia lorenese, postulata dalla critica per l'intero codice. Il copista avrebbe invece avuto sotto gli occhi un manoscritto settentrionale, e dal Nord proviene senza dubbio l'autore del poema, come emerge, nella seconda parte, dai risultati dello spoglio dei fenomeni linguistici attestati dalla rima e dalla misura, che suggeriscono anche una datazione non anteriore alla metà del XIII secolo. Queste indicazioni vengono ulteriormente precisate dall'analisi stilistica e soprattutto dall'approfondito esame delle allusioni storiche contenute nel poema, che porta Herbin a proporre l'identificazione di numerosi personaggi con figure 
legate soprattutto al regno di Luigi IX. La VF va dunque letta come una sorta di «chanson à clef» (p. 93), redatta con tutta probabilità da un autore appartenenente all'entourage del re Francia. L'indagine storica permette anche di precisare la datazione, compresa tra il 1254-55 e il 1260 o, al più tardi 1275 (termine ante, e non post quem, cfr. p. 86). Herbin mette quindi in discussione il ruolo di conclusione della Geste des Loherains tradizionalmente assegnato alla $V F$, poiché il testo «n'entre pas dans la logique de la Geste: elle l'instrumentalise» (p. 100), e in sostanza l'autore «utilise les personnages de la fiction pour servir son dessein politique et publicitaire au profit de la monarchie capétienne» (Ibidem). Un riassunto dettagliato (pp. 103-109) e una serie di cartine che localizzano i toponimi citati (pp. 110-113) aiutano il lettore ad orientarsi attraverso una narrazione non sempre lineare. Il testo è editato con cura e corredato di note esplicative e linguistiche ben documentate che apportano un contributo essenziale alla comprensione. L'indice dei nomi (pp. 393-342), esaustivo e ricco di informazioni, rettifica alcuni errori di identificazione dell'edizione Mitchneck passati poi nel repertorio di Moisan. Un glossario quasi completo (pp. 423-509) e la bibliografia (pp. 511-20) concludono questa edizione solida e accurata. 